\title{
Influence of Small Amount of Cu Addition on Microstructure, Deformation Temperature, and the Tensile Behaviour of Sn-9Zn-1.5Ag Lead free Solder Alloy
}

\author{
M.Y. Salem
}

\begin{abstract}
Physics Department, Faculty of Science, New Valley University, New Valley, 72511, El-Kharga, Egypt.
\end{abstract}

Sn-9Zn-1.5Ag and Sn-9Zn-1.5Ag-0.7Cu alloys have been inspected under different five strain rates ranging from $5.4 \times 10^{-5} \mathrm{~S}^{-1}$ to $2.9 \times 10^{-3} \mathrm{~S}^{-1}$ and different three temperatures extended from R.T. (298K) to $393 \mathrm{~K}$ for two alloys. The difference in thermal action, microstructure and stressstrain advantage related with addition of $0.7 \mathrm{Cu} w t \%$ was investigated. Transmission electronic microscope (TEM) investigation of samples revealed a homogenous uniform distribution, size refinement of IMCs and $\beta$-Sn grains. Addition of $0.7 \mathrm{Cu}$ particles into the Sn-9Zn-1.5Ag enhanced the yield stress $\sigma_{\mathrm{YS}}$ by $17 \%$ and reducing the ultimate tensile strength UTS by $12 \%$. The addition of adding $\mathrm{Cu}$ was found to be lowering ductility (total elongation) by $19 \%$ of the $\mathrm{Sn}-9 \mathrm{Zn}-1.5 \mathrm{Ag}$ solder due to the refinement of $\beta$-Sn grains; this means that $\mathrm{Sn}-9 \mathrm{Zn}-1.5 \mathrm{Ag}-0.7 \mathrm{Cu}$ is more strengthening than $\mathrm{Sn}-9 \mathrm{Zn}-1.5 \mathrm{Ag}$. The activation energy of Sn-9Zn$1.5 \mathrm{Ag}$ is lower than that of $\mathrm{Sn}-9 \mathrm{Zn}-1.5 \mathrm{Ag}-0.7 \mathrm{Cu}$; therefore first sample is more superplastic.

\section{Introduction}

Sn based alloys are convenient for refinement electronics content connections as a lead-free composite welding [1]. Lately hightemperature solders have been great utilized in different pattern of usages like aggregation optoelectronic components, auto- mobile circuit boards, circuit modules for step soldering, etc. [2,3]. Sn-9Zn is the best solder alloy for most applications in optoelectronic packaging, because of its high creep resistance, wettability and good reliability [4,5]. Certainly, high soldering temperatures could damage the properties of optical fibers and sensitive optoelectronics such as lasers, 
light emitting devices, photodetectors, or waveguide devices [6]. Significant tests have been done to improve a new propagation of solders with low melting point, Logical cost, elevated magnitude stability and supporting solder joints achievement with growing reduction and more input/output terminals [7].

Our tested alloys solder is one of great potential substitutional materials; it has a stable microstructure, good mechanical properties, high creep and corrosion strength and perfect solderability $[8,9]$. Solidification appear an essential effect because of it constitute the fundamental for improve the microstructure and consequently advance the samples quality; thus the output specimen and stabilization process possess a significant effectiveness on the feature and progressed the characteristics of cast metals [10,11]. The mechanical characteristic of the samples can be modified by gaining finer microstructure result from higher solidification rates and higher cooling rates under many solidification situations [12,13]. Liu et al. mentioned [14] that the stress-strain of the examined alloy is importantly elevated than that from the pre-tested alloy.

\section{Experimental Procedures}

Two alloys of compositions $\mathrm{Sn}-9 \mathrm{Zn}-1.5 \mathrm{Ag}$ and $\mathrm{Sn}-9 \mathrm{Zn}-1.5 \mathrm{Ag}-$ $0.7 \mathrm{Cu}$ were prepared from $\mathrm{Sn}, \mathrm{Zn}, \mathrm{Ag}$ and $\mathrm{Cu}$ raw materials with purity $99.99 \%$. These raw elements are mixed in wt. \% in ceramic crucible and melted at $450 \mathrm{C}$ for two hours. The dissolved material in the furnace is given in a mold of copper to be wire with the desired diameter. More details of composite alloys preparation are described elsewhere $[15,16]$. A cooling rate of $5-8^{\circ} \mathrm{C} / \mathrm{s}$ was achieved, so as to create the fine microstructure typically found in small solder joints in microelectronic packages. To gain samples including the completely precipitated phases, the samples were annealed at $150{ }^{\circ} \mathrm{C}$ for $1 \mathrm{~h}$, then left to cool quietly to room. This process is declaration to licence a little amount of grain growth and grain stabilization to occur $[17,18]$. The samples were examined at three temperatures ranging from $298 \mathrm{~K}$ to $393 \mathrm{~K}$ for the two alloys a waiting time $10 \mathrm{~min}$ for the test temperatures to be reached, under different strain rate ranging from $5.4 \times 10^{-5} \mathrm{~S}^{-1}$ to $2.9 \times 10^{-3} \mathrm{~S}^{-1}$, using a computerized form creep machine [18]. The chemical structure of the examined samples is registered in Table (1). The accuracy of temperature measurement is of the order $\pm 1 \mathrm{~K}$. Strain measurements were done with an accuracy of $\pm 1 \times 10^{-4}$. A solution of $2 \% \mathrm{HCl}, 3 \% \mathrm{HNO} 3$ and $95 \%$ (vol.\%) ethyl alcohol was prepared and used to etch the samples. 
Table1: Chemical composition of the studied solder alloys (wt. \%).

\begin{tabular}{llccl}
\hline Solder alloy & $\mathrm{Sn}$ & $\mathrm{Zn}$ & $\mathrm{Ag}$ & $\mathrm{Cu}$ \\
\hline Sn-9 Zn-1.5Ag & 89.5 & 9 & 1.5 & 0 \\
Sn-9Zn-1.5 Ag-0.7Cu & 88.8 & 9 & 1.5 & 0.7 \\
\hline
\end{tabular}
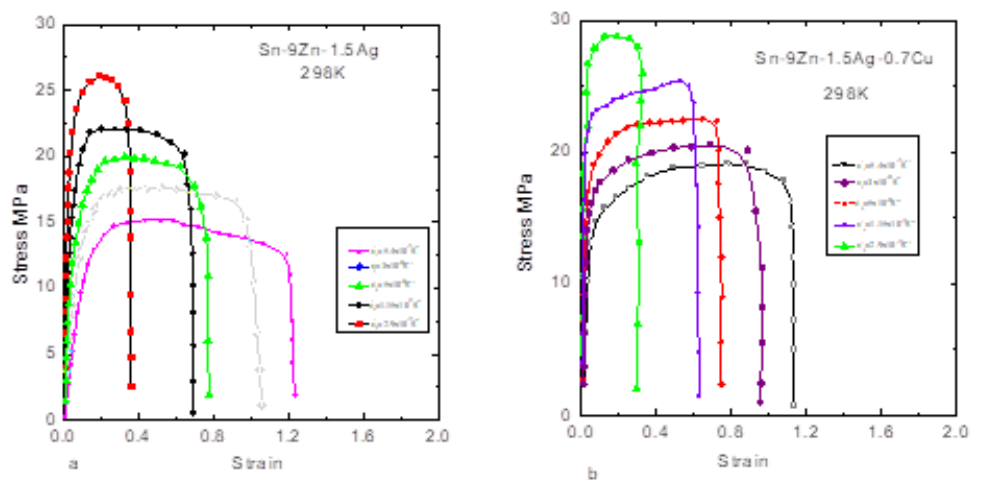

Fig.(1): Comparative tensile stress-strain curves obtained at $298 \mathrm{~K}$ and different strain rate Sn-9Zn-1.5Ag and Sn-9Zn-1.5Ag-0.7Cu solder alloys

\section{Results and Discussion}

\subsection{Mechanical Properties.}

\subsubsection{Tensile Properties}

The relation of tensile curves for two tested alloys were illustrated in Figs.(1-3) at $298 \mathrm{~K}, 333 \mathrm{~K}$, and $393 \mathrm{~K}$ at different five strain rates ranging from $5.4 \times 10^{-5} \mathrm{~S}^{-1}$ to $2.9 \times 10^{-3} \mathrm{~S}^{-1}$; it is obvious that at $298 \mathrm{~K}$ for the first sample Sn$9 \mathrm{Zn}-1.5 \mathrm{Ag}$; the stress is about $26 \mathrm{MPa}$ but for second alloy Sn-9Zn-1.5Ag-0.7 is about $28.8 \mathrm{MPa}$; while strain is 1.23 for the first one and 1.15 for the second one; this means that 0.7 increase strengthening for Sn-9Zn-1.5Ag.
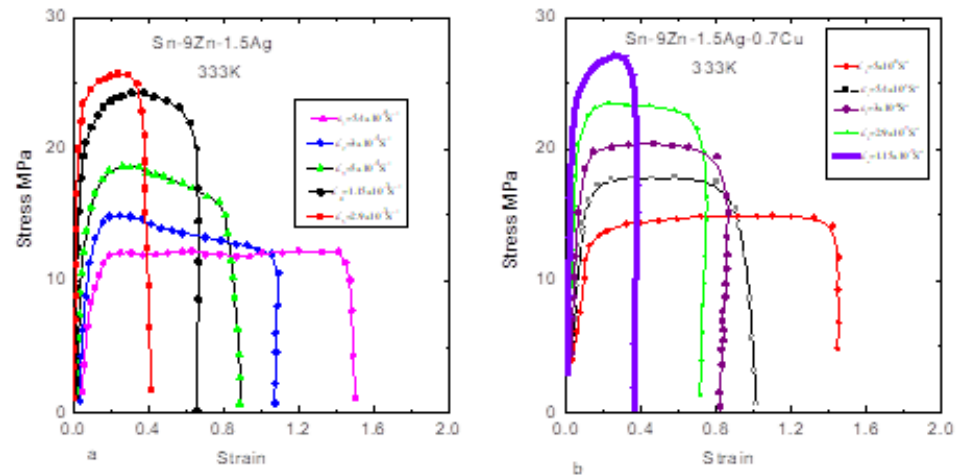

Fig.(2): Comparative tensile stress-strain curves obtained at $333 \mathrm{~K}$ and different strain rate Sn-9Zn-1.5Ag and Sn-9Zn-1.5Ag-0.7Cu solder alloys

It is clear that strain hardening appear instead of strain 
softening for all specimens due to $0.7 \mathrm{Cu}$ addition, which can be owing to the strengthening mechanism of inter metallic compound stages in the alloy matrix. However, during strain hardening is preventing dislocation activity. As the dislocation intensity rises; the impedance to their movement propagates. It is shown that the stress enhances strain hardening [19].
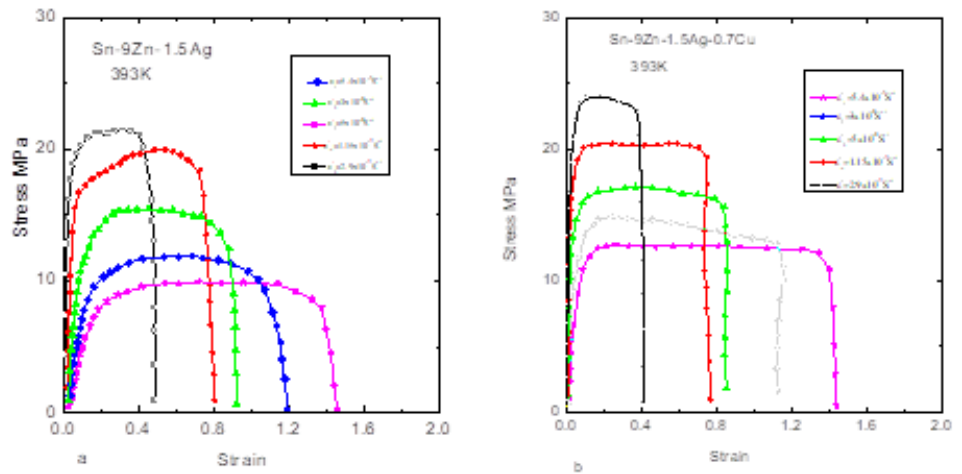

Fig.(3): Comparative tensile stress-strain curves obtained at 393K and different strain rate $\mathrm{Sn}$ 9Zn-1.5Ag and $\mathrm{Sn}-9 \mathrm{Zn}-1.5 \mathrm{Ag}-0.7 \mathrm{Cu}$ solder alloys

\subsubsection{Influence of temperature ande Young's modulus (y), yield stress $\left(\sigma_{y}\right)$, and $\sigma_{f}$}

Figure $(4 a, b)$ lists the variation of Young's modulus $(\mathrm{Y})$ with strain rate at different working temperature for $\mathrm{Sn}-9 \mathrm{Zn}-1.5 \mathrm{Ag}$ and $\mathrm{Sn}-9 \mathrm{Zn}-1.5 \mathrm{Ag}-0.7 \mathrm{Cu}$. It is clear that Young's modulus $(\mathrm{Y})$ for $\mathrm{Sn}-9 \mathrm{Zn}-1.5 \mathrm{Ag}$ samples is higher than that of Sn-9Zn-1.5Ag $-0.7 \mathrm{Cu}$ samples by about $91 \%$. It is evident that Young's modulus $(\mathrm{Y})$ is rise with rising strain rate and temperature.

In Fig.5 the differentiation of the ultimate tensile stress (UTS) with strain rate the examined samples is represented; it is shown that (UTS) for is about 26 for Sn-9Zn-1.5Ag; but equal about 29 for second alloy see Fig.(5). The Variation of yield stress $\left(\sigma_{y}\right)$ with strain rate at different working temperature for Sn-3.5Ag$0.7 \mathrm{Cu}$, and $\mathrm{Sn}-3.5 \mathrm{Ag}-0.7 \mathrm{Cu}-0.3 \mathrm{GO}$ is shown in Fig.6; it is clear the yield stress $\left(\sigma_{\mathrm{y}}\right)$ for $\mathrm{Sn}-9 \mathrm{Zn}-1.5 \mathrm{Ag}$ solders is about 24.8 but for $\mathrm{Sn}-9 \mathrm{Zn}-1.5 \mathrm{Ag}-0.7 \mathrm{Cu}$ is about 29 ; this means that $\mathrm{Sn}-9 \mathrm{Zn}-1.5 \mathrm{Ag}-0.7 \mathrm{Cu}$ is more strengthening than $\mathrm{Sn}-9 \mathrm{Zn}$ $1.5 \mathrm{Ag}$. It is evident that (UTS) and yield stress $\left(\sigma_{\mathrm{y}}\right)$ grow with growing strain rate and decrease with increasing temperature. Similar behaviour was observed by other researchers working on SAC and SC solders [20,21]. It was realized that at summit corresponding temperatures, the elongation of the material does not permanently decrease or increase with either a decrease or increase in the $\mathrm{T}$ and $\varepsilon[22]$. 

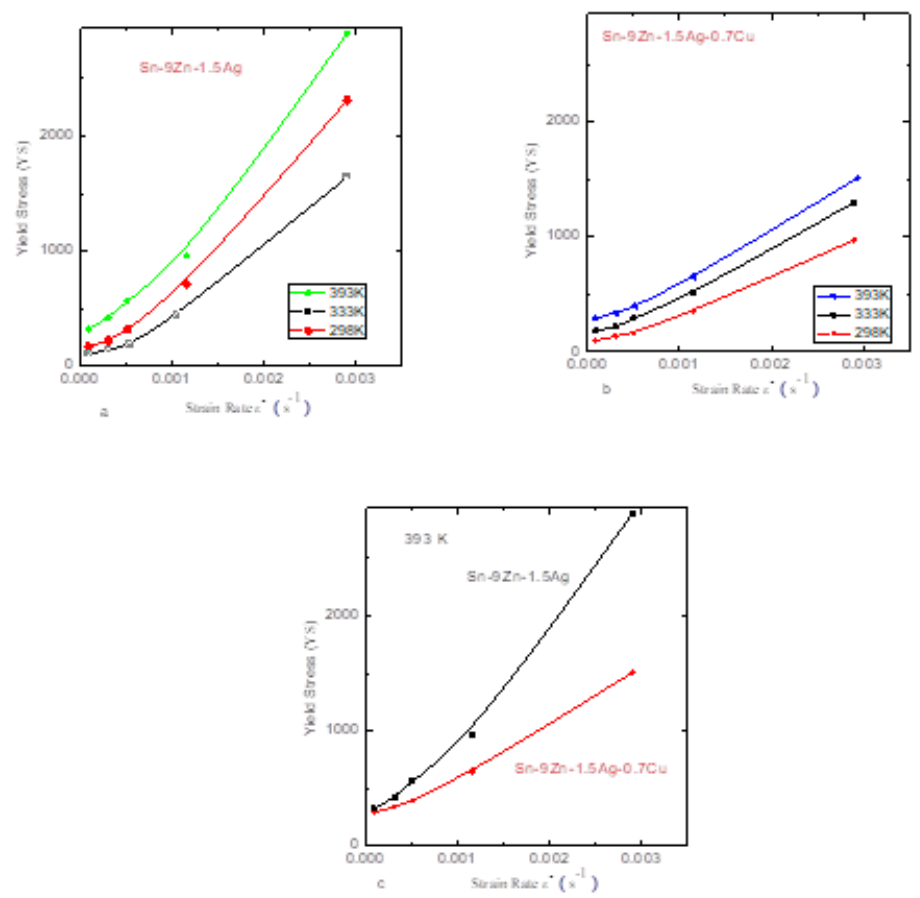

Fig.(4) a, b : The comparison of Young's modulus (Y) with strain rate at different working temperature for tested solder alloys; c) The comparison of $(\mathrm{Y})$ at fixed temperature $393 \mathrm{~K}$.

To understand that you should consider must study IMC; additional development was developed by Ashby and Edward [23] to study creep damage and failure of different materials that are degraded due to the failure of high temperatures results from different mechanisms [23].we must know that the mechanisms of damage are varied, and there are several explanations for the sensitivity of ductility in temperature testing, affect the structural effects, treatment and separation of impurities [24,25].

The relationship through the fracture strength (breaking strength) $\sigma_{\mathrm{f}}$ and strain rate at various working temperature has been examined in Fig.(7a,b); but in It is obvious that fracture strength $\left(\sigma_{\mathrm{f}}\right)$ for $\mathrm{Sn}-9 \mathrm{Zn}-1.5 \mathrm{Ag}-0.7 \mathrm{Cu}$ is more than that of $\mathrm{Sn}-9 \mathrm{Zn}-1.5 \mathrm{Ag}$; this means that $\mathrm{Sn}-9 \mathrm{Zn}-1.5 \mathrm{Ag}$ is extreme elongation. The strain rate reliance of the total elongation $\varepsilon_{\mathrm{t}}$ was constructing to follow an experimental equation of the form [26]:

$$
\varepsilon_{\mathrm{t}}=\mathrm{A} \exp \left(-\lambda \varepsilon^{\cdot}\right)
$$

where $\mathrm{A}$ and $\lambda$ are fixed constant depending on the tensile test situation.

The total strain of two alloys is interpreted in Fig.(8). However, in the 
$\mathrm{Ag}$, and $\mathrm{Cu}$ free alloy, the values of $\varepsilon_{\mathrm{T}}$ are lower with increasing temperature at all strain rates. This disagreement in the correlation between stress-strain and temperature appears to depend on the alteration in the microstructure of the samples. It is clear that $\mathrm{Sn}-9 \mathrm{Zn}-1.5 \mathrm{Ag}$ is more elongation than $\mathrm{Sn}-9 \mathrm{Zn}-1.5 \mathrm{Ag}$ $0.7 \mathrm{Cu}$.
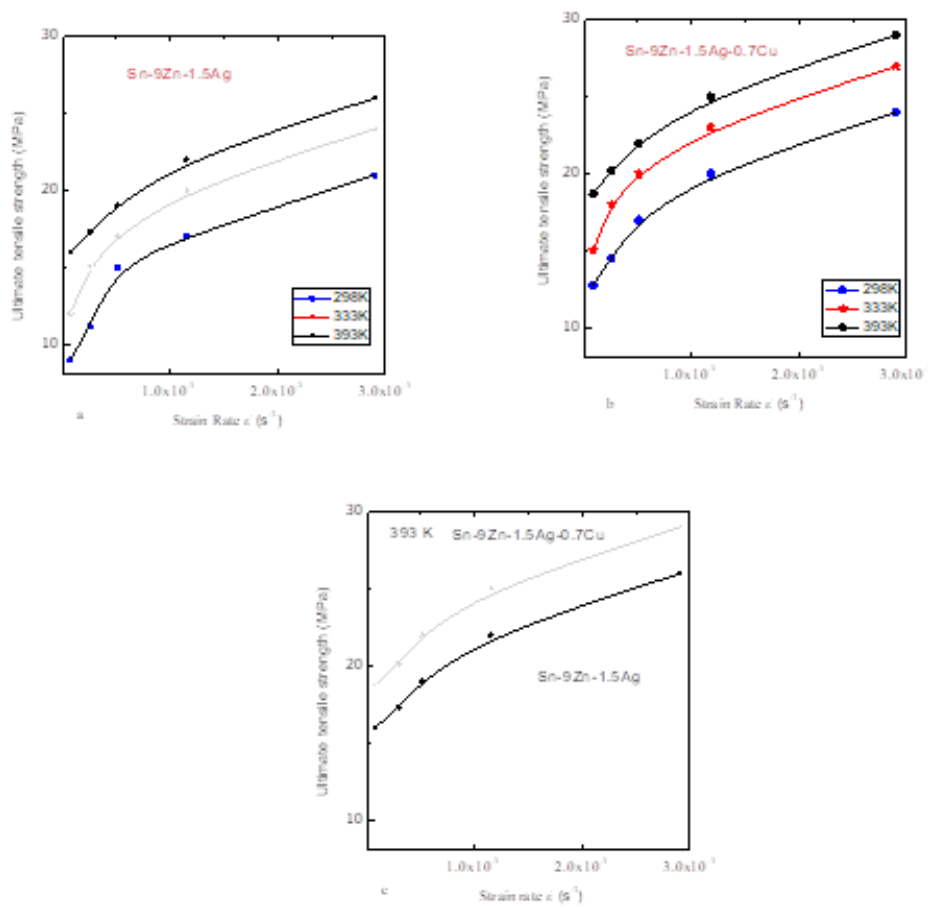

Fig.(5) a, b : The variation of the ultimate tensile stress (UTS) with strain rate at different working temperature for tested solder alloys; c) The variation of (UTS) at fixed temperature $393 \mathrm{~K}$.

We can sight that; strain rate is inversely proportional with fracture strain $\left(\varepsilon_{\mathrm{f}}\right)$ as ordinance in Fig. (9). It was celebrated that the activation energy may be estimated from the connection between $\ln$ (fracture strain $\varepsilon_{\mathrm{f}}$ ) with 1000/T at several working temperature are illustrated in Fig.(10 a, b). The value of activation energy with temperature for solders is described in Fig.(10c). The activation energy of $\mathrm{Sn}-9 \mathrm{Zn}-1.5 \mathrm{Ag}-0.7 \mathrm{Cu}$ alloy is higher than that of $\mathrm{Sn}-9 \mathrm{Zn}-$ $1.5 \mathrm{Ag}$; there fort first samples is more strengthening (less in elongation) than the second.

\section{2-Stress exponent}

The activation energy and stress exponent (n) are significant thermodynamic and mechanical factors to characterize the creep deformation mechanisms of samples [27]. In general, the deformation aforethought by diffusion mechanism can be determines by [21]: 


$$
\dot{\varepsilon}=\mathrm{A}^{\mathrm{n}}
$$

where $\dot{\varepsilon}$ is the strain rate, is the stress and A is the materialdependent constant [27]. The deformation mechanism is diffusion it can be characterised by equation (2) [23].
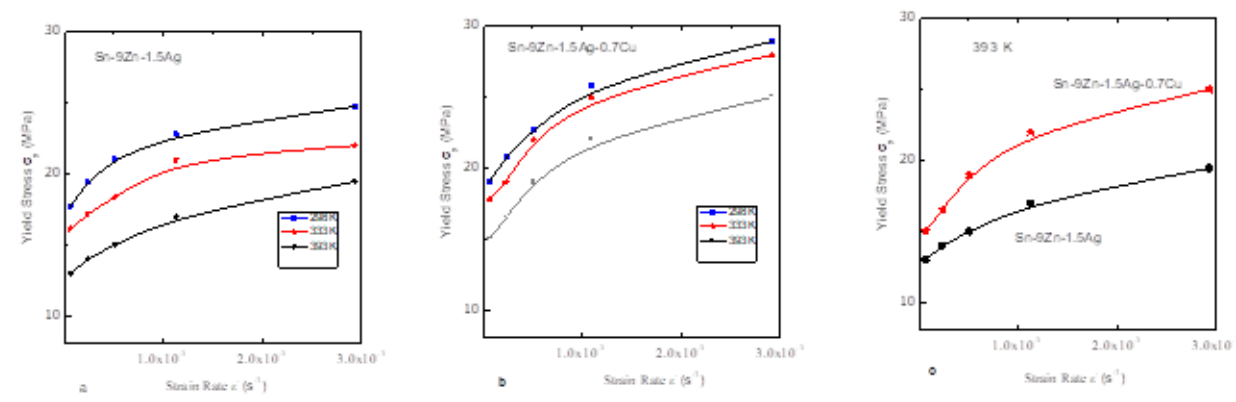

Fig.(6) a, b : The variation yield strength $\left(\sigma_{y}\right)$ with strain rate at different workíng temperature for tested solder alloys; c) The variation of $\left(\sigma_{\mathrm{y}}\right)$ at fixed temperature $393 \mathrm{~K}$.

Figure (11) shows a linear relationship between UTS and strain rate $(\log -\log$ plot), and the slope of each line (fitted to the experimental data) gives the so-called stress exponent, $n$. The $n$ values at different temperatures for the tested alloys are listed in Table 2,3. It is clear that the value of stress exponent, $\mathrm{n}$ of Sn-9Zn-1.5Ag$0.7 \mathrm{Cu}$ alloy is above than that of $\mathrm{Sn}-9 \mathrm{Zn}-1.5 \mathrm{Ag}$. In this paper (stress exponent $\mathrm{n} \geq 4$ ), therefore the controlling mechanism is dislocation climb [28]. Fig.(12) a. demonstrated XRD manner for first alloy where Ag, Zn, and $\mathrm{Sn}$ appear and (b) for $\mathrm{Sn}-9 \mathrm{Zn}-1.5 \mathrm{Ag}-0.7 \mathrm{Cu}$; the $\mathrm{Ag}_{3} \mathrm{Sn}$ morphology was confirmed in the XRD model of tested samples, showing the effective alloying of $\mathrm{Sn}$ and $\mathrm{Ag}$ after the melting process. At the same time, the $\mathrm{Cu}_{6} \mathrm{Sn}_{5}$ and $\mathrm{Cu}_{3} \mathrm{Sn}$ phases were formed, which were due to the alloying of $\mathrm{Sn}$ and $\mathrm{Cu}$ in the $\mathrm{Sn}-9 \mathrm{Zn}-1.5 \mathrm{Ag}-0.7 \mathrm{Cu}$ alloy. Furthermore, the comparative density of $\beta-\mathrm{Sn}$ was established to be slightly lowered with the increase of $\mathrm{Cu}$, due to the structure of $\mathrm{Cu}_{6} \mathrm{Sn}_{5}$ and $\mathrm{Cu}_{3} \mathrm{Sn}$ phases.
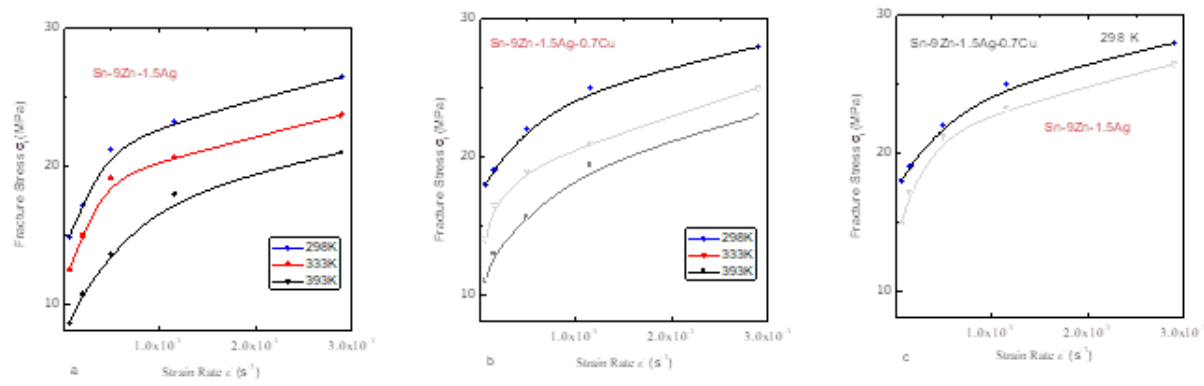

Fig.(7) a, b : The variation of fracture strength $\left(\sigma_{\mathrm{f}}\right)$ with strain rate at different working temperature fortested solder alloys; c) The variation of $\left(\sigma_{\mathrm{f}}\right)$ at fixed temperature $298 \mathrm{~K}$. 

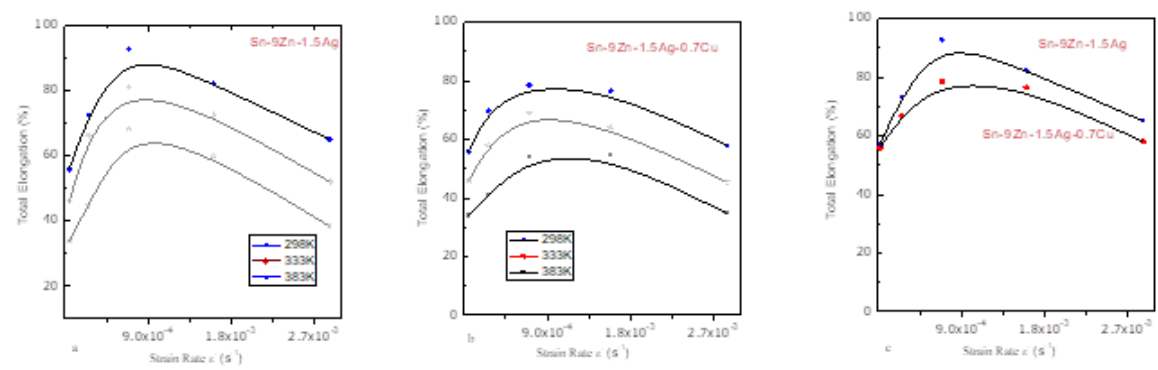

Fig.(8) a, b : The variation of total elongation $(\varepsilon)$ with strain rate at different working temperature for tested solder alloys; c) The variation of total elongation $(\varepsilon)$ at fixed temperature $298 \mathrm{~K}$.
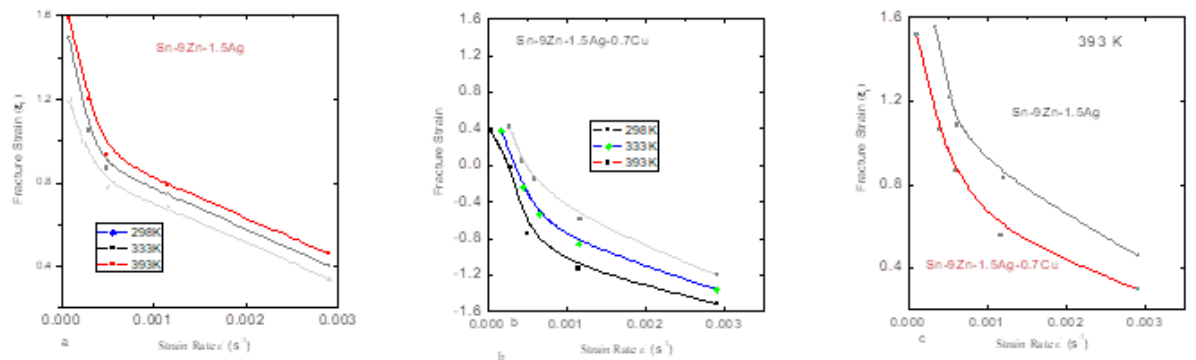

Fig.(9) a, b : The variation fracture strain $\left(\varepsilon_{\mathrm{f}}\right)$ with strain rate at different working temperature for tested solder alloys; $c$ ) The variation of fracture strain $\left(\varepsilon_{\mathrm{f}}\right)$ at fixed temperature $393 \mathrm{~K}$.
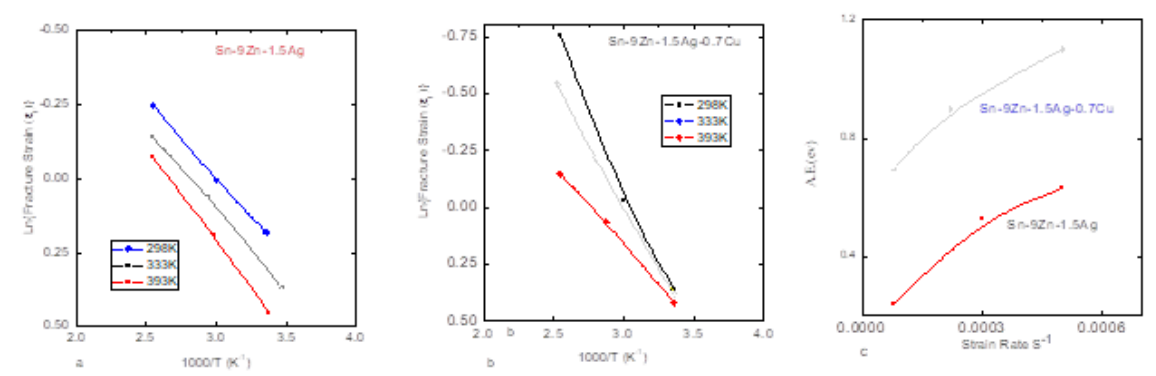

Fig.(10): a, b: the relation between $\ln$ fracture strain $\left(\varepsilon_{\mathrm{f}}\right)$ with 1000/T at different working temperature for tested alloys,c; The activation energy with strain rate for tested alloys.

Fig.(13) a: represented EDS images of the tested alloys, the microstructure composed of $\beta$-Sn areas, fine $\mathrm{Ag}_{3} \mathrm{Sn}$ precipitates. In Fig.3.b, analysis of the tested alloys. This observation implies that the needle-like phases are the $\mathrm{Cu}_{6} \mathrm{Sn}_{5}$ IMCs, while the $\mathrm{Cu}_{3} \mathrm{Sn}$ IMC, and also, the fine particles dispersed in the $\beta$-Sn phase were determined. In Fig.(14) SEM images of the alloys microstructure composed of light gray areas of $\mathrm{Cu}_{6} \mathrm{Sn}_{5}$ IMCs and dark network-like eutectic regions of $\beta$-Sn and 
white area of $\mathrm{Ag}_{3} \mathrm{Sn}$. A small addition of $\mathrm{Ag}$ into the $\mathrm{Sn}-9 \mathrm{Zn}$ alloy produced many small spheroidal particles within the like-eutectic regions and they were determined to be $\mathrm{Ag}_{3} \mathrm{Sn}$ IMC phase. The reason may be that the $\mathrm{Cu}$ addition promotes a high nucleation density of the second phase in the $\mathrm{Sn}-9 \mathrm{Zn}$ during solidification.
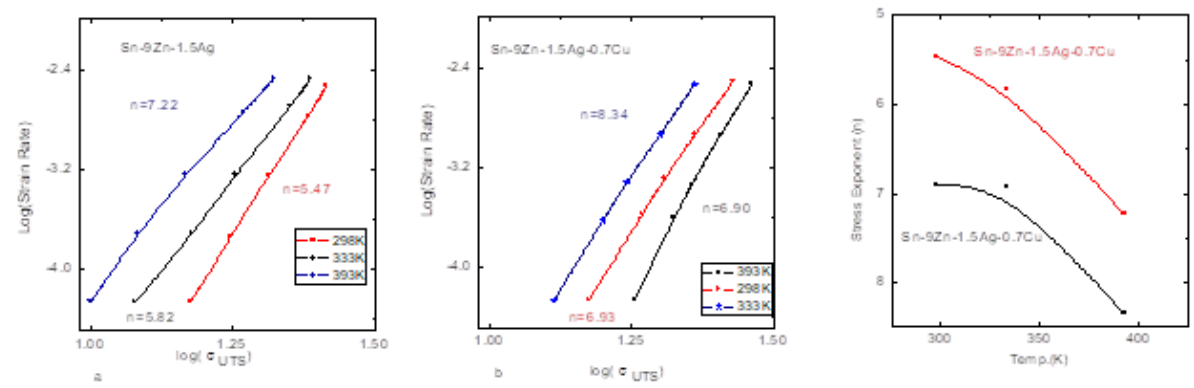

Fig.(11): a,b: shows a line are relationship between UTS and strain rate (log-log plot), and the slope of each line (fitted to the experimental data); c gives the so-called stress exponent.
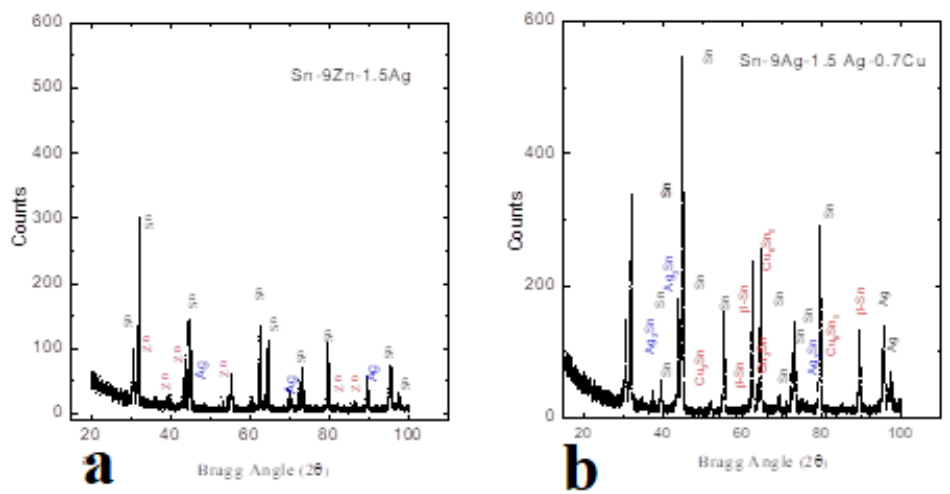

Fig. (12) a. XRD patternfor Sn-9Zn-1.5Ag alloy where Ag, Zn, and Sn appear and (b)for Sn-9Zn-1.5Ag-0.7Cu mainly composed of $\beta$-Sn phase exhibited additional IMCs such as $\mathrm{Ag}_{3} \mathrm{Sn}, \mathrm{Cu}_{6} \mathrm{Sn}_{5}$.

Table (2): Tensile parameters of $\mathrm{Sn}-9 \mathrm{Zn}-1.5 \mathrm{Ag}$

\begin{tabular}{llllllll}
\hline Temp. K & $\mathrm{Y}$ & $\sigma_{\mathrm{y}}$ & $\sigma_{\mathrm{f}}$ & $\mathrm{UTS}$ & $\varepsilon_{\mathrm{f}}$ & $\mathrm{n}$ & $\varepsilon_{\mathrm{t}} \%$ \\
\hline 298 & 2894 & 24.75 & 26.7446 & 1.59 & 5.47 & 93 \\
333 & 2312 & 22 & 23.7 & 24 & 1.49 & 5.82 & 81 \\
393 & 1647 & 19.4521 & 21 & 1.2 & 7.22 & 68 \\
\hline
\end{tabular}


a

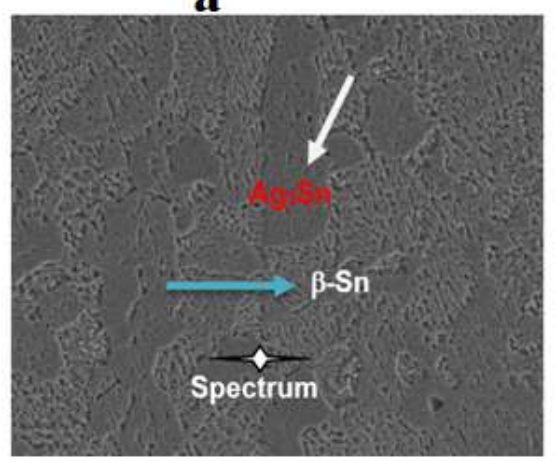

b

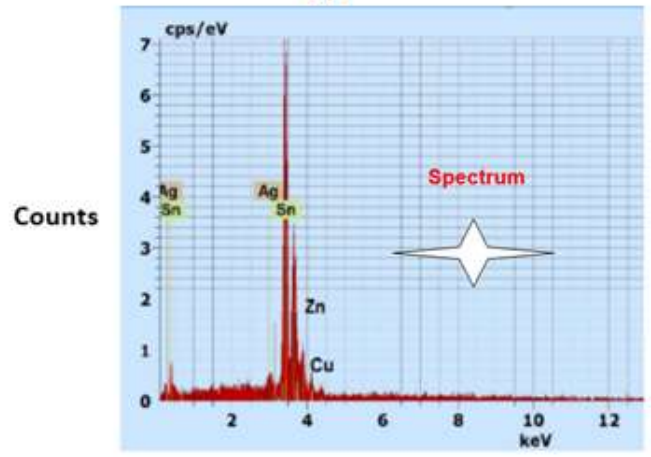

Spectrum: Acquisition

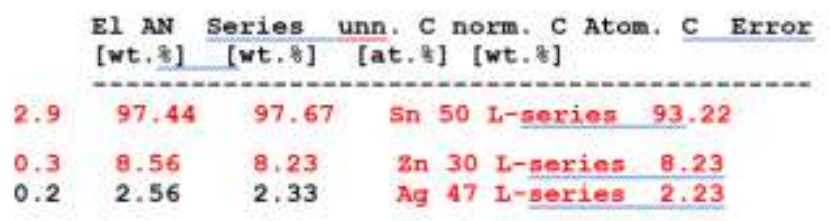

Total $\neq 100.00$

Fig.(13) a: represented SEM images of the tested alloys, the microstructure composed of $\beta$-Sn areas, fine $\mathrm{Ag}_{3} \mathrm{Sn}$ precipitates. In Fig.3.b, EDS analysis of the tested alloys.
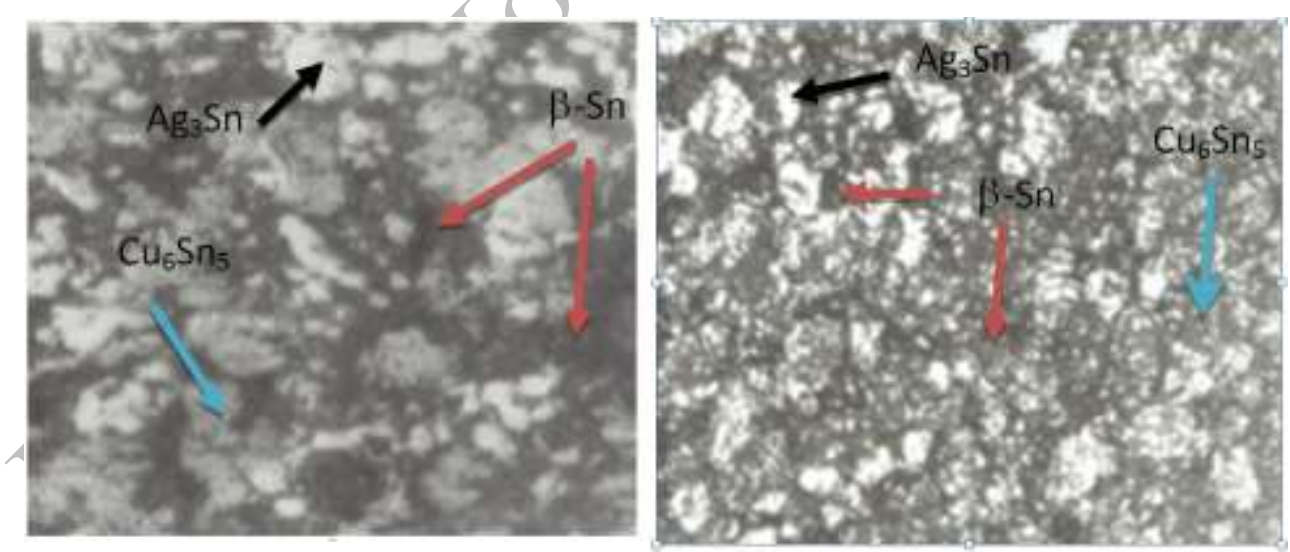

Fig.(14):The SEM images of the alloys microstructure composed of light gray areas of $\mathrm{Cu}_{6} \mathrm{Sn}_{5} \mathrm{IMCsand}$ dark network-like eutectic regions of $\beta$-Sn and white area of $\mathrm{Ag}_{3} \mathrm{Sn}$. 
Table (3): Tensile parameters $\mathrm{Sn}-9 \mathrm{Zn}-1.5 \mathrm{Ag}-0.7 \mathrm{Cu}$

\begin{tabular}{llllllll}
\hline Temp. K & $\mathrm{Y}$ & $\sigma_{\mathrm{y}}$ & $\sigma$ & UTS & $\varepsilon_{\mathrm{f}}$ & $\mathrm{n}$ & $\varepsilon_{\mathrm{t}} \%$ \\
\hline 298 & 1511 & 29 & 2 & 29 & 1.5 & 6.9 & 78. \\
333 & 1300 & 28 & 2 & 27 & 1.4 & 6.9 & 69 \\
393 & 972 & 25 & 2 & 24 & 1.4 & 8.3 & 53 \\
\hline
\end{tabular}

\section{Conclusion}

1- The total elongation $\varepsilon_{\mathrm{T}}$ are decrease with rising temperature at all strain rates.

2- This disagreement in the correlation between stress-strain and temperature appears to depend on the alteration in the microstructure of the samples.

3- The $\mathrm{Sn}-9 \mathrm{Zn}-1.5 \mathrm{Ag}-0.7 \mathrm{Cu}$ is more strengthening than $\mathrm{Sn}-9 \mathrm{Zn}-1.5 \mathrm{Ag}$; i.e. it is clear that $\mathrm{Sn}-9 \mathrm{Zn}-1.5 \mathrm{Ag}$ is more elongation than $\mathrm{Sn}-9 \mathrm{Zn}-1.5 \mathrm{Ag}-0.7 \mathrm{Cu}$; therefore the activation energy of $\mathrm{Sn}-9 \mathrm{Zn}-1.5 \mathrm{Ag}$ is minimize than second alloy.

\section{References:}

1. M. Abtew, G. Selvaduray, Mater. Sci. Eng., R 27, 95 (2000).

2. V. Chidambaram, J. Hattle, J. Hald, Microelectron. Eng., 88, 981 (2011).

3. A.N. Fouda, E.A. Eid; Materials Science \& Engineering, A 632, 82 (2015). 7

4. H. Mavoori, S. Jin, J. Electron. Mater., 27 (11), 1216 (1998).

5. L.C. Tsao, S.Y. Chang, Mater. Des. 31, 990 (2010).

6. H. Mavoori, JOM 52 (6), 29 (2000).

7. J. Shen, Y.C. Chan, Microelectron. Reliab. 49, 223 (2009).

8. J. Rodney, McCabe, E. Morris, Metall. Mater. Trans. A 33A, 1531. (2002).

9. M.D. Mathew, H. Yang, S. Movva, K.L. Morty, Metall. Mater. Trans. A 36A, 99. (2005).

10. A. Verma, SP. Tewari, J. Prakash, Journal of Engineering Science and Technology., 3(6):5215 (2011).

11. M. Y. Salem and A.S.Mahmoud, Egypt. J. Solids, Vol. (40), 39, (2017) Verissimo NC, Brito C, Santos WLR, Cheung N, Spinelli JE, Garcia A., Journal of Alloys and Compounds. 662, 1 (2016).

12. Zhang B, Li X, Wang T, Liu Z., Materials Science and Engineering: A. 674, 242 (2016).

13. Liu K, Jiang Z, Zhao J, Zou J, Chen Z, Lu D. Journal of Alloys and Compounds.; 612, 221 (2014). 
14. A.A. El-Daly, A. Fawzy, S.F. Mansour, M.J. Younis, Mater Sci Eng A; 578, 62, (2013).

15. A.A. El-Daly, A. Fawzy, S.F. Mansour, M.J. Younis, J. Mater Sci: Mater Electron 24; 2976 (2013).

16. M.Y. Salem, Egypt. J. Solids, Vol. (39); 107 (2016).

17. Salem M.Y. International Journal of New Horizons in Physics Vol. 4, No. 2 , 21 (2017).

18. C. Andersson, P. Sun, J. Liu, J. Alloys Compd., 457, 97 (2008).

19. F. Zhu, H. Zhang, R. Guan, S. Liu, Microelectron. Eng., 84, 144 (2007).

20. Q.S. Zhu, Z.G. Wang, S.D. Wu, J.K. Shang, Mater. Sci. Eng. A 502, 153 (2009).

21. A.A. El-Daly, Phys. Stat. Sol., A 201 (9), 2035 (2004).

22. G.H. Edward, M.F. Ashby, Acta Metall., 27, 1505 (1979).

23. A.A. El-Daly, A.E. Hammad, Mater. Sci. Eng., A 527, 5212 (2010).

24. A.A. El-Daly, A.E. Hammad, Journal of Alloys and Compounds, 509, 8554 (2011).

25. Fawzy. A; Effect of $\mathrm{Zn}$ addition, strain rate and deformation temperature on the tensile properties of $\mathrm{Sn}-3.3 \mathrm{wt} \% \mathrm{Ag}$ solder alloy Materials Characterization 58, 323 (2007).

26. Z. Liang, X. Song-bai, G. Li-li, Z. Guang, C. Yan, Y. Sheng-lin, S. Zhong, Trans. Nonferr. Met. Soc. Chin. 20, 412 (2010).

27. R. Mahmudi, A.R. Geranmayeh, H. Khanbareh, N. Jahangiri, Mater. Des. 30, 574 (2009). 